\title{
Kaufmann, Thomas, Schubert, Anselm, Greyerz, Kaspar von, Frühneuzeitliche Konfessionskulturen. Erste Nachwuchstagung des VRG Wittenberg 30.09.-02.10.2004
}

Philippe Büttgen

\section{OpenEdition}

Journals

Édition électronique

URL : http://journals.openedition.org/ifha/1687

DOI : 10.4000/ifha.1687

ISSN : 2198-8943

Éditeur

IFRA - Institut franco-allemand (sciences historiques et sociales)

Référence électronique

Philippe Büttgen, «Kaufmann, Thomas, Schubert, Anselm, Greyerz, Kaspar von, Frühneuzeitliche Konfessionskulturen. Erste Nachwuchstagung des VRG Wittenberg 30.09.-02.10.2004 », Revue de l'IFHA [En ligne], Date de recension, mis en ligne le 01 janvier 2008, consulté le 22 septembre 2020. URL : http:// journals.openedition.org/ifha/1687 ; DOI : https://doi.org/10.4000/ifha.1687

Ce document a été généré automatiquement le 22 septembre 2020.

(C)IFHA 


\title{
Kaufmann, Thomas, Schubert, Anselm, Greyerz, Kaspar von, Frühneuzeitliche Konfessionskulturen. Erste Nachwuchstagung des VRG Wittenberg 30.09.-02.10.2004
}

\author{
Philippe Büttgen
}

\begin{abstract}
Ces deux recueils sont à lire comme la mise en œuvre d'une proposition historiographique sur les «cultures confessionnelles » lancée il y a dix ans par une première étude de Th.K. sur la guerre de Trente ans (Dreißigjähriger Krieg und Westfälischer Frieden. Kirchengeschichtliche Studien zur lutherischen Konfessionskultur, Tübingen : Mohr, 1998) ainsi que par la synthèse de K.v.G. sur Religion und Kultur 1500-1800 (Göttingen : Vandenhoeck \& Ruprecht, 2000). Par rapport au premier état de la discussion, l'accent semble s'être légèrement déplacé. À l'origine, les Konfessionskulturen renvoyaient au choix d'une " perspective interne " (Innenperspektive) sur les croyants de l'époque moderne, dans laquelle devaient se réunir leur " perception de soi » (Selbstverständnis) et leur « environnement concret » (Lebenswelt). Chacun de ces termes était porteur d'une protestation contre le paradigme de confessionnalisation dans sa version " standard ", avec son fonctionnalisme (la pluralité des confessions s'étudie pour sa contribution à la naissance de l'État moderne), le lissage qu'elle opère des particularités confessionnelles et son approche essentiellement systémique des interactions politiques et sociales. Le recueil Konfession und Kultur préfère parler des " relations " qui définissent le luthéranisme de la seconde moitié du XVIe s., la relation à soi constituant un cas parmi d'autres qui incluent en particulier la perception luthérienne du judaïsme ou - dans une vaste étude inédite résumée dans le recueil de Heinz Schilling Konfessioneller Fundamentalismus (voir compte rendu plus bas) - la propagande anti-jésuite. D'autres études portent sur l'apocalyptique, notamment au tournant de l'an 1600, sur la question du culte des images, la constitution du canon textuel luthérien, la formation
\end{abstract}


des pasteurs, l'expertise des théologiens ou les réactions protestantes à la Paix d'Augsbourg après 1555. La caractéristique générale de l'« identité luthérienne » tracée dans les " Prolégomènes " de l'ouvrage reprend l'essentiel des résultats de 1998 : culture menacée, "dos au mur » face à l'activisme de ses concurrents catholiques ou réformés et compensant ses certitudes apocalyptiques par une non moins implacable théologie de l'ordre, le premier luthéranisme après Luther partage avec son époque l'ensemble de ses traits "défensifs voire dépressifs» (p. 25) en y ajoutant encore le handicap dû à sa grande fragmentation - ou " pluralité » (p. 16) - doctrinale. Comme en 1998 encore, c'est d'abord par des considérations de périodisation que Th.K. entend justifier son propos. Cette fois l'accent est mis sur ce qui relie les décennies de la Réforme à celles qui courent de la mort de Luther à l'orée de la guerre de Trente ans : nouveau continuum, qui impose la séquence 1517-1600 comme celle de la Konfessionskultur luthérienne proprement dite, face à la chronologie essentiellement politique que privilégient les tenants de la confessionnalisation en allant, pour l'essentiel, de 1555 à 1648 . On est bien entendu tenté de s'interroger sur ce qu'il en est de la continuité de la culture confessionnelle luthérienne au-delà de 1600 . Une question similaire est posée par l'application de la notion aux autres confessions, sa possibilité, ses effets propres. Si quelques travaux comme ceux d'A. Holzem commencent à évoquer une culture confessionnelle catholique, les essais rassemblés dans l'autre recueil sur les Frühneuzeitliche Konfessionskulturen font toujours pencher la balance du côté des confessions issues de la Réforme. L'apport spécifique de ce volume d'Actes sera plutôt à chercher dans l'extension internationale qui y est tentée, avec plusieurs comparaisons et cas de transfert entre France et Empire (E. Kammerer, J. Kümmerle), auxquels s'ajoute l'espace helvétique (J. Blakeley). Ce sont là, il est vrai, les questions classiques qu'on pose à tout concept neuf en histoire : extension chronologique, spatiale et - dans le cas d'espèce - religieuse. Il se peut que la Konfessionskultur garde ici un sens foncièrement protestant et germanique, homonyme seulement à ce qui peut se désigner sous l'appellation d'une " culture catholique », en raison d'un autre rapport à l'espace, au territoire, à la création intellectuelle et artistique et au fait même d'être désigné comme « confession » quand on se donne pour l'Église universelle. Sur ce point, les deux nouvelles dimensions que Th.K. confère à l'étude des cultures confessionnelles - celle de leur diversité constitutive et celle de leur persistance au-delà des rythmes politiques (p. 13-14) - donneront à coup sûr la possibilité d'effectuer les vérifications nécessaires. Pour cette discussion qui doit se poursuivre sur les Konfessionskulturen, elles ont le très grand mérite de faire émerger, pour la première fois aussi clairement dans le contexte historiographique allemand, la catégorie même du confessionnel (das Konfessionelle) comme question et défi à la confessionnalisation.

Philippe Büttgen (Centre National de la Recherche Scientifique) 